\title{
Beryllium-Ceramic Compatibility Tests
}

\section{Los Alamos


This work was supported by the U.S. Department of Energy-Materials Disposition.

An Affirmative Action/Equal Opportunity Employer

This report was prepared as an account of work sponsored by an agency of the United States Government. Neither The Regents of the University of California, the United States

Government nor any agency thereof, nor any of their employees, makes any warranty, express or implied, or assumes any legal liability or responsibility for the accuracy, completeness, or usefulness of any information, apparatus, product, or process disclosed, or represents that its use would not infringe privately owned rights. Reference herein to any specific commercial product, process, or service by trade name, trademark, manufacturer, or otherwise, does not necessarily constitute or imply its endorsement, recommendation, or favoring by The Regents of the University of California, the United States Government, or any agency thereof. The views and opinions of authors expressed herein do not necessarily state or reflect those of The Regents of the University of California, the United States Government, or any agency thereof. Los Alamos National Laboratory strongly supports academic freedom and a researcher's right to publish; as an institution, however, the Laboratory does not endorse the viewpoint of a publication or guarantee its technical correctness. 
Beryllium-Ceramic Compatibility Tests

Robert J. Hanrahan, Jr. 


\title{
Beryllium - Ceramic Compatibility Tests
}

\author{
Robert J. Hanrahan, Jr. \\ Los Alamos National Laboratory \\ Materials Science and Technology Division \\ MST-6 Materials Technology - Metallurgy
}

\begin{abstract}
We are interested in the possibility of using induction melting in order to recycle beryllium components. This process will require the use of a container for the molten $\mathrm{Be}$. Although $\mathrm{BeO}$ is the obvious choice of materials based on compatibility, engineering considerations dictated that other materials be considered. Therefore, a series of experiments was performed in order to test the compatibility of molten beryllium with various ceramic crucible materials. The materials tested include $\mathrm{Al}_{2} \mathrm{O}_{3}, \mathrm{Y}_{2} \mathrm{O}_{3}, \mathrm{MgO}$, $\mathrm{ZrO}_{2}, \mathrm{SiC}$ and $\mathrm{SiO}_{2}$ (fused silica). Alumina exhibited the best compatibility among the materials tested, based on the relatively trivial observation that the molten beryllium did not stick to alumina. We have evaluated the reaction products and to some extent the mechanism of reaction of beryllium with each of these materials. In the case of alumina for example, the compatibility may be attributed to the formation of a layer of an intermediate $\mathrm{BeO}-\mathrm{Al}_{2} \mathrm{O}_{3}$ phase or phases. In the magnesia, yttria, and zirconia-Be systems ternary oxides are not observed but the oxides may be reduced by beryllium resulting in formation of intermetallic phases and beryllium oxide. The silicon based compounds are reduced to form $\mathrm{BeO}$ and free silicon. The significance of these results with regard to the published thermodynamic data (particularly phase diagrams) will be discussed. Additional tests were conducted to evaluate the products of the reaction between molten beryllium and stainless steel. This report also discusses the results of these tests.
\end{abstract}

\section{Be-SS Alloy Tests}

These tests were conducted in order to experimentally evaluate the possibility of lowering the melting point of the resulting mix. Elemental beryllium was melted (using DC arc) with samples of 304 stainless steel. Ingots were cross sectioned to evaluate microstructure and determine composition using $\mathrm{x}$-ray diffraction. The resulting microstructures revealed a mixture of intermetallic compounds such as $\mathrm{CrBe}_{2}\left(\mathrm{~T}_{\mathrm{mp}} 1840^{\circ}\right.$ C) $\mathrm{NiBe}\left(\mathrm{T}_{\mathrm{mp}} 1605^{\circ} \mathrm{c}\right)$ and $\mathrm{FeBe}_{2}\left(\mathrm{~T}_{\mathrm{mp}} 1463^{\circ} \mathrm{C}\right)$. The true liquidus temperature of the resulting alloy is above the allowed temperature limit of the DTA system available for beryllium work $\left(1400^{\circ} \mathrm{C}\right)$ therefore precise melting points could not be determined. Although eutectics exist in all of these systems the lowest melting points are only marginally below that of $\mathrm{Be}\left(1289^{\circ} \mathrm{C}\right)$. In a crucible experiment these intermetallic compounds can be expected to form at the interface between the molten Be and SS, resulting in a reaction rate that is limited by diffusion across the intermetallic layer. In the case of solid-solid reactions Flament et al. have calculated the rate of interdiffusion across the reaction zone. ${ }^{1}$ Although the rates may be expected to be much higher in the case of molten Be-SS reaction complete reaction is unlikely to be achieved in a reasonable time without stirring and the use of the maximum available furnace temperatures. 


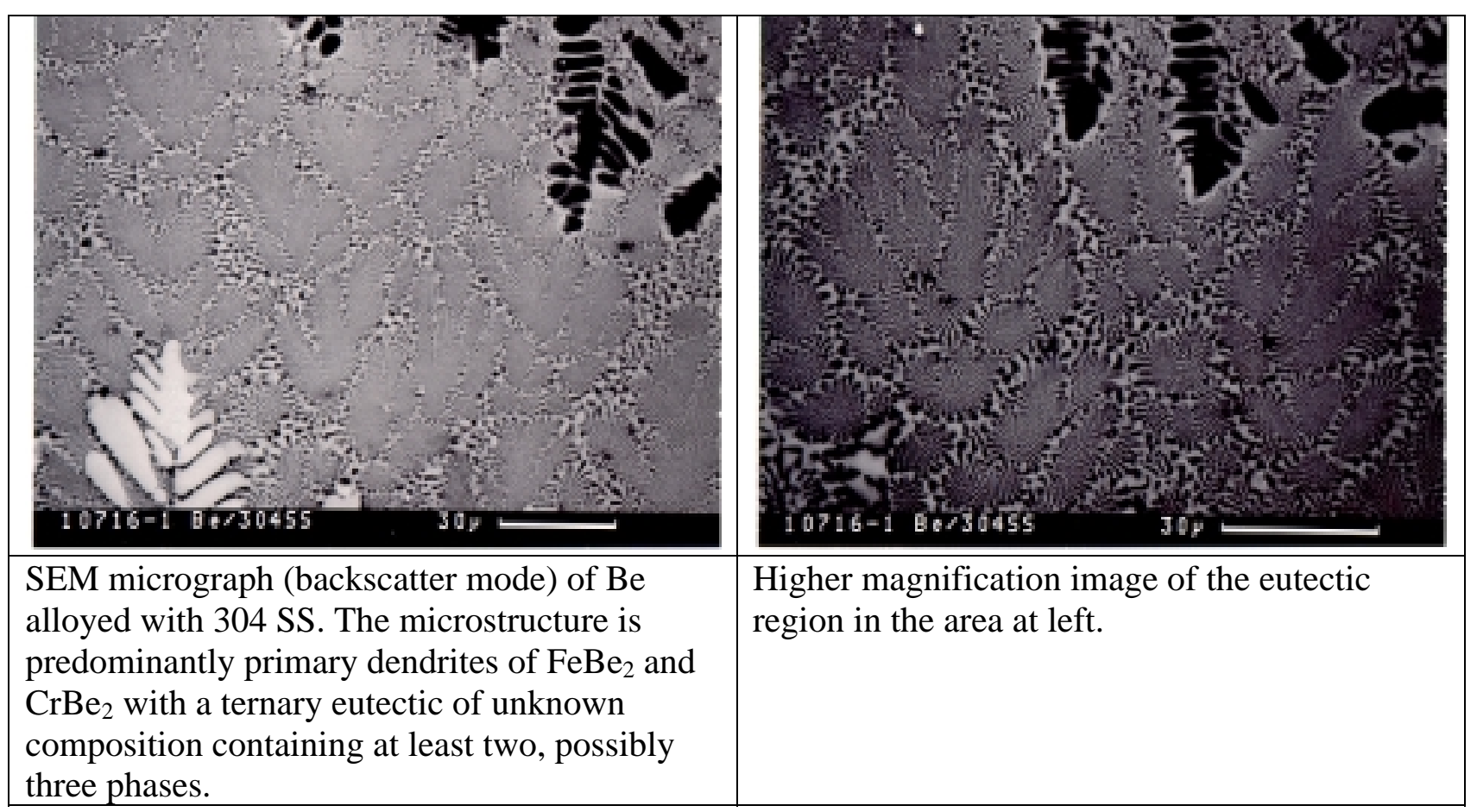

\section{Beryllium - Crucible Compatibility Tests}

The objective of this series of experiments was to determine the compatibility and (if compatible) optimum heating and cooling rates for ceramic crucibles used to melt beryllium metal. Compatibility was evaluated based on the condition of the crucible (no cracks or holes) and the extent of interaction between the crucible and the beryllium (if the beryllium stuck to the crucible, what and how much reaction product formed). Crucible materials were chosen based on available thermodynamic information, previous experience, and availability.

Materials are listed in alphabetical order rather than the order in which they were tested. All experiments were conducted at furnace temperatures of $1350^{\circ}$ or $1400^{\circ} \mathrm{C}$ in a 2" i.d. Lindberg tube furnace unless otherwise noted.

\section{Alumina}

Early experience in using $\mathrm{Al}_{2} \mathrm{O}_{3}$ crucibles for melting Be in the DTA had revealed that the Be stuck to the crucible indicating some reaction. Furthermore, discussions with personnel in the beryllium team indicated that alumina had been observed (by workers at Brush-Wellman) to result in $\mathrm{Al}$ contamination of the resulting Be melt. Therefore this material was initially eliminated from consideration. Only after all of the other materials evaluated had failed to produce completely satisfactory results was it tested. Commercially available crucibles produced by Coors Ceramics Co. were used in these tests. The results of these tests revealed that alumina was sufficiently compatible with molten Be to allow its use as a crucible for melting Be (as long as slight amounts of $\mathrm{Al}$ contamination are not a concern). The beryllium did not stick to the crucible but fell out as a smooth ball. It appears that the surprisingly good compatibility of alumina and beryllium is attributable to the formation of the thin barrier layer visible in the 
micrograph below. X-ray diffraction indicated that this layer consisted of $\mathrm{BeO}$ and $\mathrm{Al}_{2} \mathrm{O}_{3}$. The layer is thick enough that we cannot rule out the presence of additional ternary phases within the layer. There are three identified ternary compounds in the $\mathrm{BeO}-\mathrm{Al}_{2} \mathrm{O}_{3}$ system. $^{2}$ These intermediate compounds may act as barriers to further reaction. In any case this reaction product also explains the apparent reaction in the much smaller and narrower DTA crucibles. No intermetallic compounds exist in the $\mathrm{Be}-\mathrm{Al}$ system which may also contribute to the relatively high compatibility observed in these tests.

(Examples of systems where intermetallic compound formation is observed are discussed below.)

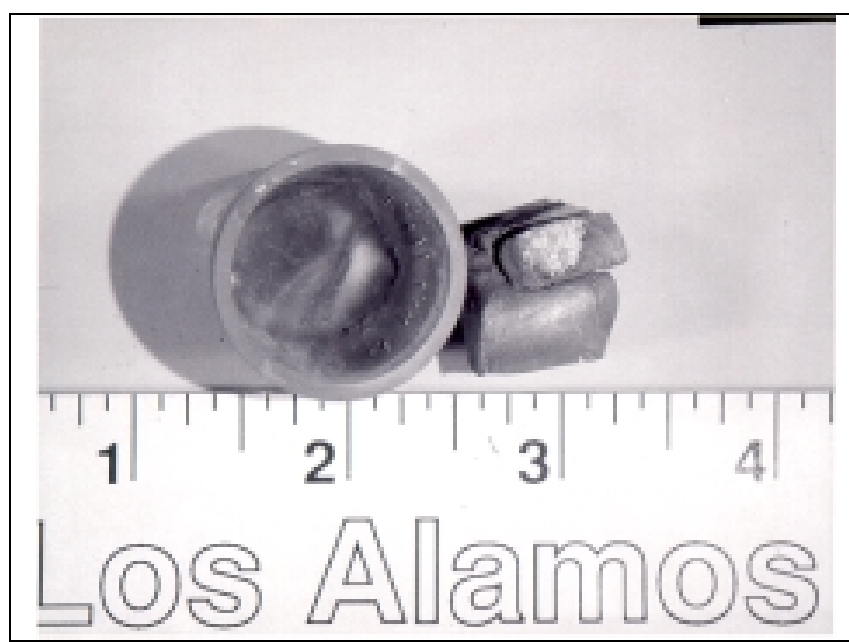

Alumina crucible used for melting Be. This crucible was exposed cyclically, for a total exposure of 6 hours at $1400^{\circ} \mathrm{C}$.

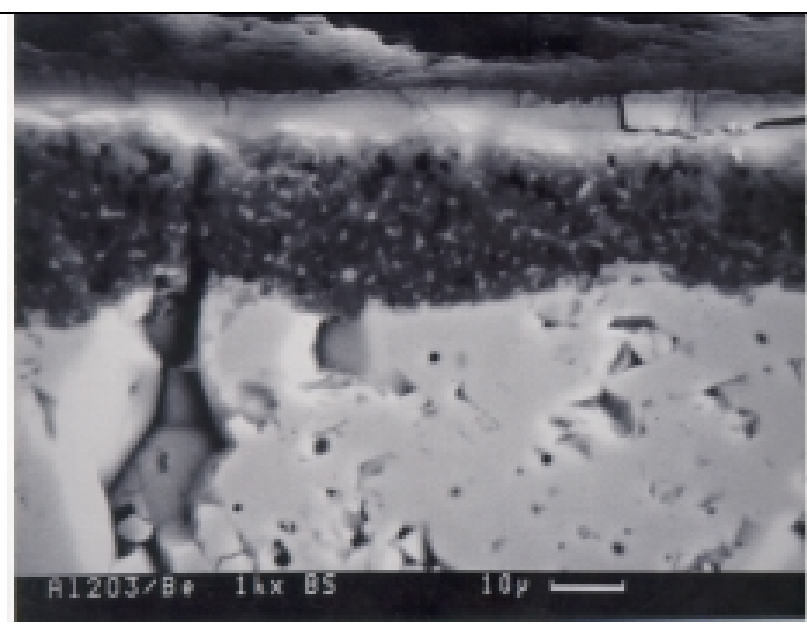

SEM image of a cross section taken from the bottom of the crucible at left. The light layer at the bottom is alumina, the dark layer above the center of the micrograph is the reaction product $\left(\mathrm{BeO}-\alpha \mathrm{Al}_{2} \mathrm{O}_{3}\right)$. (The layer at top is mounting material).

\section{Boron Nitride}

Boron nitride is often recommended for molten metal handling as it is generally considered resistant to metal wetting. For optimum strength and hardness compositions containing other inorganic compounds (ceramic alloys) are often specified (see ZSBN below).

Pure self bonded boron nitride crucibles, grade AX05 were obtained from Carborundum Corp.

Inconsistent results were obtained in these tests. In the first test no obvious reaction was noted, although the crucible cracked (at left below). In later tests the Be was observed variously to stick to the sides of the crucible, while in some tests apparently localized reactions resulted in cracking and escape of the molten Be from the crucible. The reaction products have not been completely identified at this time. In any case $\mathrm{BN}$ is apparently not appropriate as a crucible material for melting Be. 


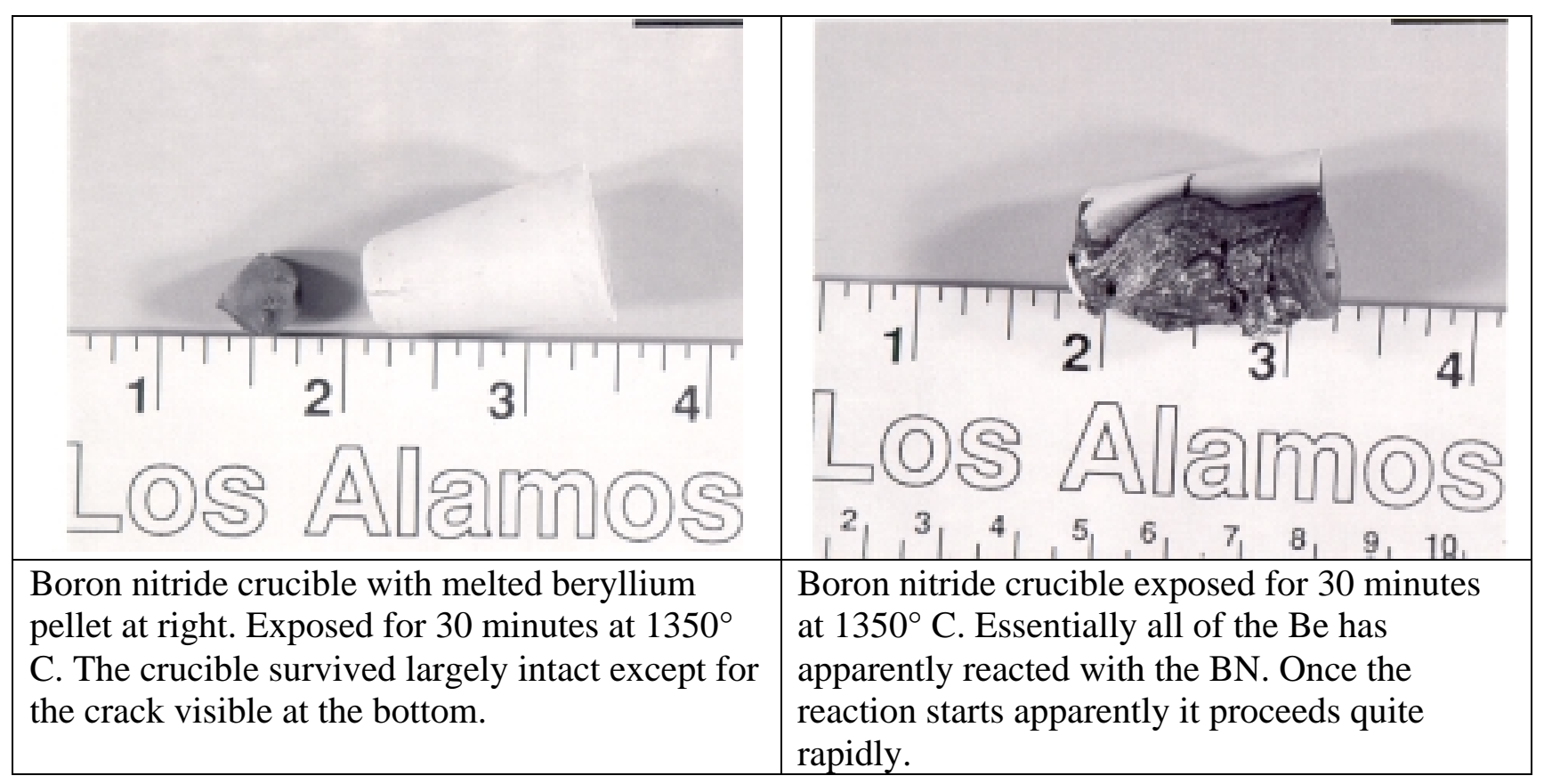

\section{Magnesia (MgO)}

The molten beryllium stuck to the side of the crucible. The principle reaction product was $\mathrm{BeO}$. The reactions expected in this system are (similar to $\mathrm{Y}$ and $\mathrm{Zr}$ oxide systems discussed below)

$$
\begin{aligned}
& \mathrm{MgO}+\mathrm{Be}=\mathrm{BeO}+\mathrm{Mg} \\
& \mathrm{Mg}+13 \mathrm{Be}=\mathrm{MgBe}_{13}
\end{aligned}
$$

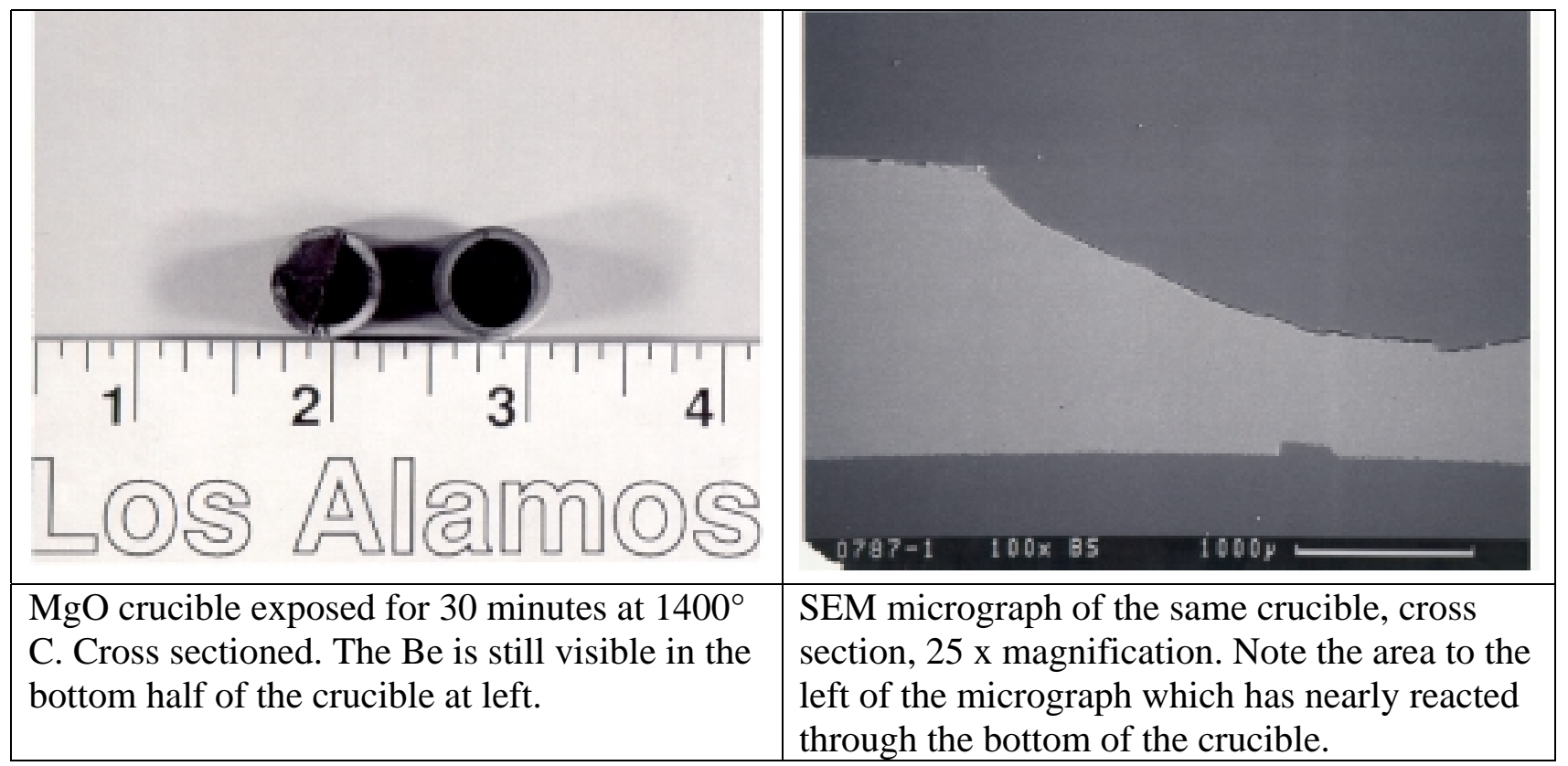




\section{Silica (fused silica)}

Very nearly complete reaction was observed. The products were not identified but are expected to be $\mathrm{BeO}$ and $\mathrm{Si}$ (see the discussion of silicon carbide results below).

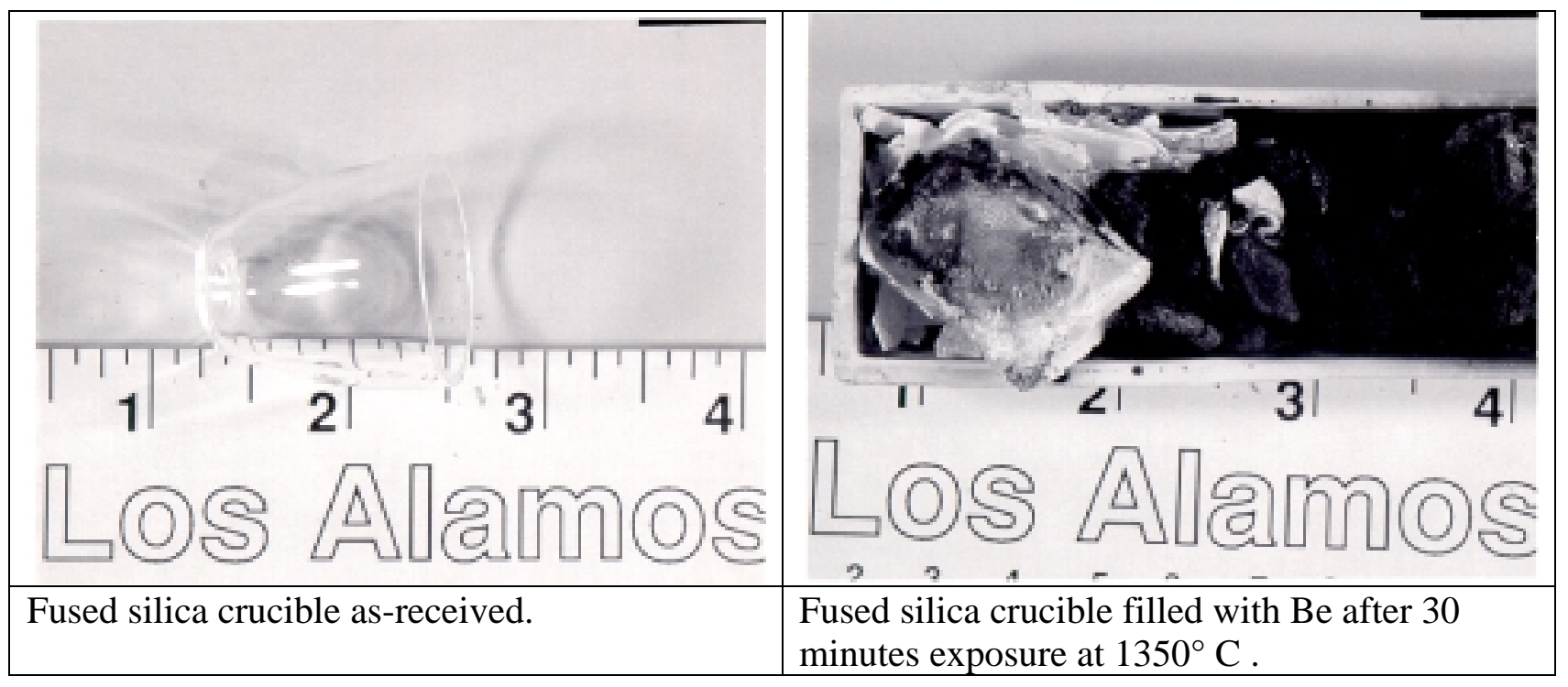

\section{Silicon Carbide}

The published Be-C-Si diagram is for a $1000^{\circ} \mathrm{C}$ isotherm ${ }^{3}$. Equilibria are indicated between $\mathrm{Si}$ and $\mathrm{Be}_{2} \mathrm{C}$ and $\mathrm{SiC}$ and $\mathrm{Be}_{2} \mathrm{C}$. Therefore at the interface between molten $\mathrm{Be}$ and $\mathrm{SiC}$ one would expect that the reaction products would be $\mathrm{Be}_{2} \mathrm{C}$ and elemental $\mathrm{Si}$. This suggests the possibility that $\mathrm{SiC}$ could actually be compatible with molten $\mathrm{Be}$, if the beryllium carbide formed acted as a diffusion barrier. The first test of 30 minutes at $1350^{\circ} \mathrm{C}$ resulted in Be stuck to the crucible. A second test for 2 hours resulted in a nearly complete reaction of the $\mathrm{Be}$ with the $\mathrm{SiC}$. The reaction products were identified as $\mathrm{Be}_{2} \mathrm{C}$ and elemental silicon. (This verifies that in the ternary system $\mathrm{Si}-\mathrm{Be}-\mathrm{C}$ there is an equilibrium tie line between $\mathrm{Si}$ and $\mathrm{Be}_{2} \mathrm{C}$ at $1350^{\circ} \mathrm{C}$.) An attempt was made to cross section the less reacted crucible, (at left below) in order to observe the morphology of the reaction front, however the available saw was not up to the task. We can however conclude that the beryllium carbide layer was not in fact protective. 


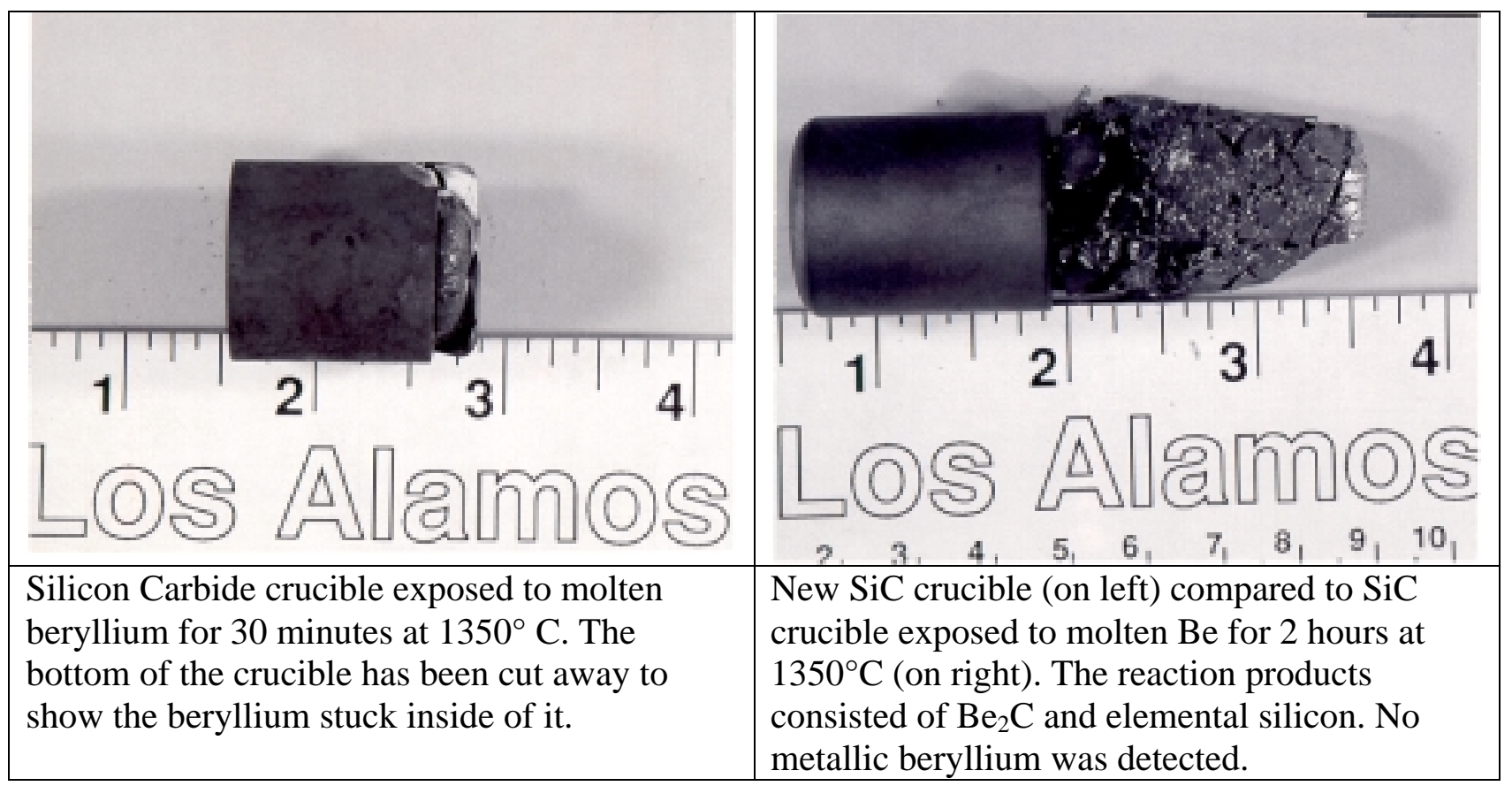

\section{Yttrium Oxide (Yttria)}

The beryllium clearly reacted with the crucible (i.e. the metal stuck to the side of the crucible). Observing the cross section of this crucible in the figure below, several different reaction products are visible. In the optical micrograph at top left there is clearly a network of some second phase distributed throughout the beryllium (this phase has not yet been identified). A fractured area is visible near the beryllium/yttria interface but no obvious reaction product is visible. At higher magnification a single layer of product is visible. The reaction product was identified as $\mathrm{BeO}$, hence the molten beryllium reduced the yttrium. An intriguing aspect of this study is the intermediate layer visible between the $\mathrm{Be}$ and $\mathrm{BeO}$ in the backscattered image below on the right (the thicker layer). The contrast suggests that this is a compound whose average $\mathrm{Z}$ lies between $\mathrm{BeO}$ and $\mathrm{Be}$. Although the stabilities of $\mathrm{Y}_{2} \mathrm{O}_{3}$ and $\mathrm{Al}_{2} \mathrm{O}_{3}$ are similar, there are no known stable ternary compounds in the $\mathrm{BeO}-\mathrm{Y}_{2} \mathrm{O}_{3}$ psuedobinary system (under reducing conditions). ${ }^{4}$ Some compounds have been reported under oxidizing conditions but the existence of a phase similar to $\mathrm{BeO}-\mathrm{Al}_{2} \mathrm{O}_{3}$ has not been confirmed. ${ }^{4,5,6}$ The most likely explanation is the formation of the intermetallic compound $\mathrm{Ybe}_{13}$. This is also consistent with the reaction sequence

$\mathrm{Y}_{2} \mathrm{O}_{3}+3 \mathrm{Be}=2 \mathrm{Y}+3 \mathrm{BeO}$

$\mathrm{Y}+13 \mathrm{Be}=\mathrm{YBe}_{13}$

Based on the stoichiometry of the reaction we can calculate the expected relative thickness of the reaction layers (by comparing the relative molar volumes and number of moles of each product from the reaction). The intermetallic layer would be expected to be approximately 11 times the thickness of the $\mathrm{BeO}$ layer, based on the relative densities of these phases. This is in fact observed in the micrographs below. Furthermore, the planar 
appearance of the reaction layers suggests that the reaction does proceed via the two steps outlined above.

In any case yttria is clearly unsuitable for containment of molten Be.

\begin{tabular}{|l|l|}
\hline \\
$\begin{array}{l}\text { SEM micrograph (backscatter electron image) of } \\
\text { the cross section of an yttrium oxide crucible } \\
\text { exposed to molten beryllium for 30 minutes at } \\
\begin{array}{l}1400^{\circ} \mathrm{C} \text {. The reaction product is the gray band } \\
\text { above the white yttria matrix. A network of } \\
\text { another reaction product is visible as white } \\
\text { tendrils in the solidified beryllium (black in this } \\
\text { image). }\end{array}\end{array} \quad \begin{array}{l}\text { Higher magnification micrograph of the } \\
\text { interface region in the cross section at right } \\
\text { are visible above the (fractured) yttria crucible } \\
\text { matrix. Based on thermodynamics and a } \\
\text { simple mass balance it is concluded that these } \\
\text { layers are BeO (thick upper layer) and YBe } \\
\text { (thin inner layer). }\end{array}$ \\
\hline
\end{tabular}




\section{Zirconia}

The molten beryllium obviously reacted with the $\mathrm{ZrO}_{2}$, as it clearly wet the side of the crucible and stuck to it. The extent of the reaction was not evaluated. However when the sample was cross sectioned the Be separated from the $\mathrm{ZrO}_{2}$. However given that the dimensions of the crucible and the overall appearance of the beryllium were nearly identical to the yttria and $\mathrm{MgO}$ cases discussed above, the reaction product is expected to be nearly identical. (Except in the case of $\mathrm{ZrO}_{2}$ we might expect to see two intermetallics in the intermediate layer.) The extent of the reaction was sufficiently limited however that it is possible that this material could be used as a disposable crucible.

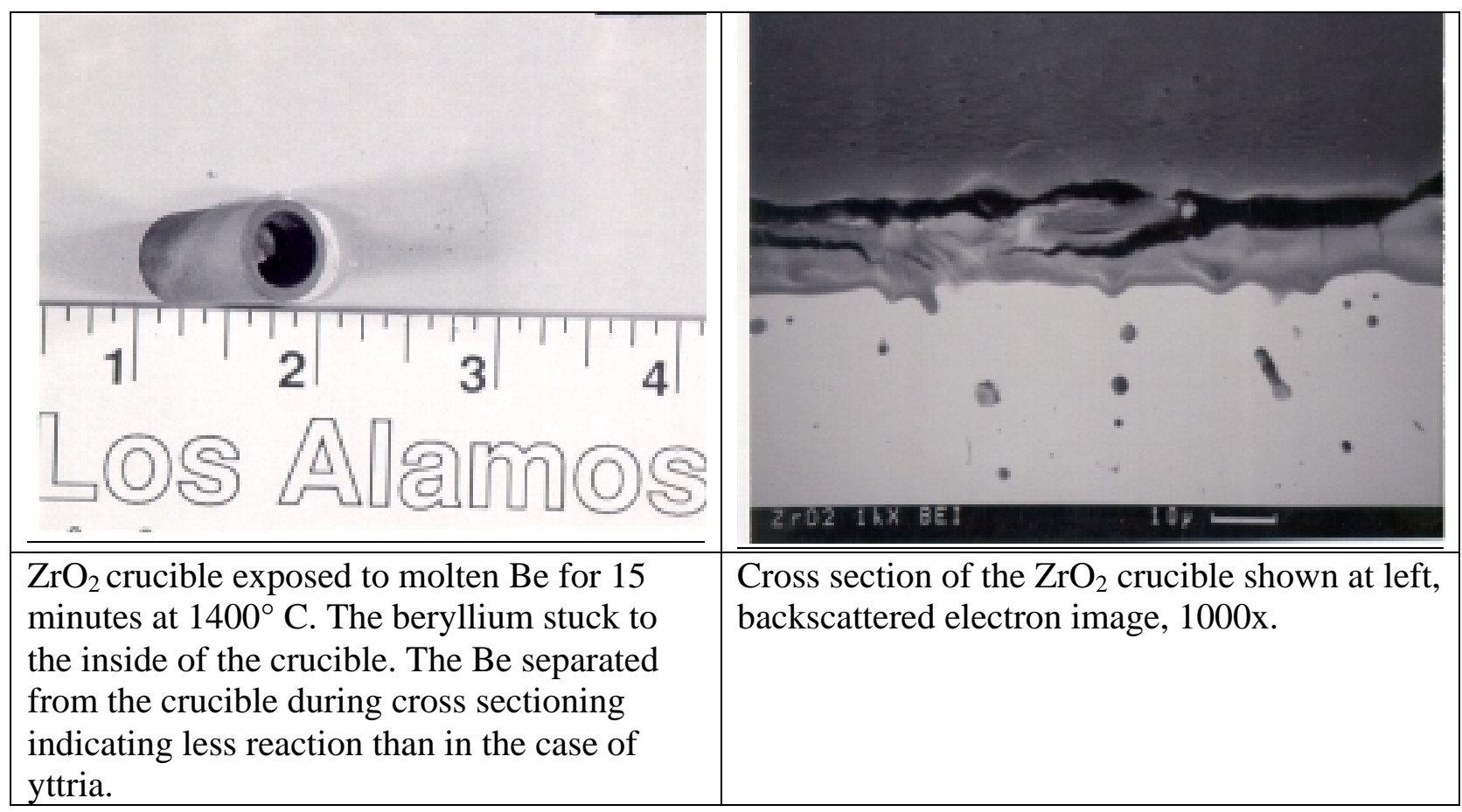

\section{ZSBN}

ZSBN is a ceramic alloy of zirconia, boron nitride, and silicon carbide. This material is used to manufacture nozzles used for plasma spraying of molten metals. Therefore it was considered a potentially compatible material. Results were inconsistent in terms of the failure mode however no tests indicated full compatibility.

Crucibles were purchased from Carborundum corp. The dimensions were identical to the boron nitride discussed above.

According to the manufacturer's website (http://www.carbobn.com/mainitems/mainframe.html), "Grade ZSBN is composed of boron nitride, zirconia and small amounts of silicon carbide, offers superior hardness and wear resistance. It is the material of choice for breakrings and other molten metal applications. This composite material combines the thermal performance and machinability of boron nitride with the strength and corrosion resistance of zirconia and silicon carbide." 
In retrospect since the pure components were not compatible with the molten Be the failure of the ZSBN crucibles is not surprising.

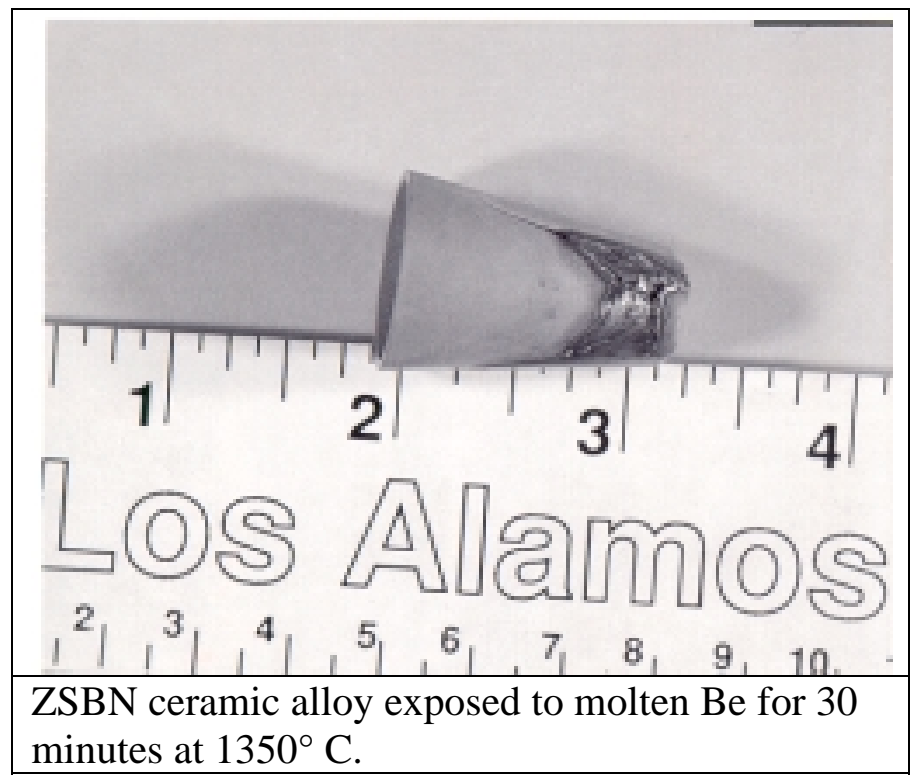

\section{References}

1. Flament, T., Herpin, D., Feve, L., and Sannier, J., J. Nucl. Mat, 191, pp 163-7, 1992.

2. F. Ya. Galakhov, Izv. Akad. Nauk SSR Otdel. Khim. English Translation, (1957) 1062-7.

3. Handbook of Ternary Alloy Phase Diagrams, P. Villars, A. Prince, and H. Okamoto eds. ASM International, Materials Park Ohio, 1995, p 6007.

4. Otto, H.E., and Bobeck, G. E., "A Phase Diagram Study of the $\mathrm{BeO}-\mathrm{Y}_{2} \mathrm{O}_{3}-\mathrm{ZrO}_{2}$ System in Reducing Atmospheres," report DRI-2194, Denver Research Institute, 1964.

5. Weir, C.E., and Van Valkenberg, A. "Studies of Beryllium Chromite and Other Beryllia Compounds with $\mathrm{R}_{2} \mathrm{O}_{3}$ Oxides," J. Research N.B.S. 64A, No. 1, pp 103-106, 1960.

6. Bartram, S.F., "Preliminary Report of X-Ray Studies on the BeO- $\mathrm{Y}_{2} \mathrm{O}_{3}$ System" Report DC-61-7-10, General Electric Aircraft Nuclear Propulsion Division, 1961. 
This report has been reproduced directly from the best available copy. It is available electronically on the Web (http://www.doe.gov/bridge).

Copies are available for sale to U.S. Department of Energy employees and contractors from-

Office of Scientific and Technical Information

P.O. Box 62

Oak Ridge, TN 37831

(423) 576-8401

Copies are available for sale to the public from-

National Technical Information Service

U.S. Department of Commerce

5285 Port Royal Road

Springfield, VA 22616

(800) 553-6847 


\section{Los Alamos \\ NATIONAL LABORATORY \\ Los Alamos, New Mexico 87545}

